\title{
Pengendalian Banjir Terhadap Sungai Jragung Dukuh Wangun Rejosari Kecamatan Karangawen Kabupaten Demak
}

\author{
Lilis Suryawati ${ }^{1 *}$, Lintang Jata ${ }^{1}$ \\ *Corresponding email: lilisecha14@gmail.com \\ ${ }^{1}$ Mahasiswa Program Studi Teknik Sipil, Fakultas Teknik, UnikaSoegijapranata, Semarang
}

\begin{abstract}
Abstrak
Banjir merupakan bagian dari salah satu bencana alam yang sering terjadi khususnya di Kabupaten Demak,terutama daerah Jragung,Sayung,Karang Asem dan Mranggen.Dampak terjadinya banjir yang tidak bisa kita hindari,membuat kerusakan rumah-rumah warga sekitar,kerusakan insfrastruktur kota hingga robohnya jembatan dan merugikan sosial ekonomi di kawasan Kabupaten Demak akibat yang terkena genangan banjir dan waktu genangan yang cukup lama.Dari jurnal yang saya akan tulis dengan judul Pengendalian Banjir terhadap Sungai Jragung bertujuan untuk mereduksi dan menanggulangi limpasan yang terjadi akibat debit banjir di Kawasan Kabupaten Demak dengan beberapa pengetahuan yang saya ketahui.Air merupakan kebutuhan pokok yang harus dipenuhi oleh makhluk hidup.Begitupun dengan air yang jumlahnya banyak sehingga menyebabkan potensi kerusakan alam,misal banjir dll.Maka dari itu air perlu dikelola dan dikendalikan dengan sedemikian rupa agar bermanfaat bagi kehidupan masyarakat.Dengan begitu kita harus memperhatikan semakin pesatnya pertumbuhan penduduk Indonesia khusunya sistem Sungai Jragung,penyediaan air didalam dimensi waktu,ruang,jumlah dan mutu menjadi masalah yang serius didalam tata guna lahan pada Daerah Aliran Sungai dari sistem Sungai Jragung.Dalam penanganan banjir dengan mengurangi kondisi sungai yang mengalami penyempitan yang disebabkan olehsedimentasi.
\end{abstract}

Kata kunci : Sumber Daya Air,Pengendalian Banjir,Perbaikan Sungai.

\begin{abstract}
Floods are part of one of the natural disasters that often occur especially in Demak Regency, especially in the Jragung, Sayung, Karang Asem and Mranggen areas. The impact of flooding that we cannot avoid causes damage to local residents' houses, damage to city infrastructure and collapse of bridges. and detrimental to the socio-economy in the Demak Regency area due to being affected by flood inundation and long inundation time. From the journal I will write with the title Flood Control of the Jragung River aims to fight and eradicate runoff that occurs due to flood discharge in Demak Regency with several The knowledge that I know. Water is a basic need that must be fulfilled by living things. Likewise with large amounts of water that causes potential damage to nature, for example floods etc. Therefore, water needs to be managed and controlled in such a way as to benefit people's lives. so we have to considering the rapid growth of Indonesia's population, especially the Jragung River system, water supply in the dimensions of time, space, quantity and quality has become a serious problem in land use in the watershed of the Jragung River system. In handling floods by reducing the condition of the river which is narrowing due to sedimentation.
\end{abstract}

Keywords: Water Resources, Flood Control, River Improvement.

\section{PENDAHULUAN}

Banjir sudah menjadi bencana alam yang rutin terjadi bagi warga Kota
Demak,Semakin harinya semakin bertambah persoalannya dan membuat repot dalam penanganannya bagi 
Pemerintah Kota untuk mencari solusi yang tepat dalam mengatasi masalah banjir. Banjir yang melanda Dukuh Wangun Desa Rejosari Kecamatan Karangawen Demak pada pertengahan Januari lalu akibat Sungai Cabean yang tidak mampu menahan debit air.

Cara penanganan bendung sungai Jrangung di bendung Ploso dan Guntur dengan bantuan Gubernur Jawa Tengah Ganjar Pranowo SH MIP,Pada hari Rabu,18 Maret 2017 sungai cabean yang sudah tidak dapat menampung debit air sungai Jragung. Saat dibangun proyek Jratunseluna, harapannya dapat membagi debit air. Namun, faktanya tidak berhasil.

"Pada kala masih pemabagian debit dibangunnya Jratunseluna,Air yang seharusnya belok ke arah Sungai Jragung dan Cabean tidak kembali normal,padahal faktanya $60 \%$ sudah diterima Sungai Cabean dan 40\% dengan sungai Jragung".

Bahwasanya dijelaskan bahwa perbaikan pengairan sungai Jragung sudah masuk dalam Program Kementerian Pekerjaan Umum dan Perumahan Rakyat. Saat ini memasuki tahap Detail Engineering Desaign (DED). Proyek pembaungan direncanakan awal tahun 2018 dengan BBWS Pemali Juwana.Secara yang sudah terencana awal pembagian penanganan terbagi terhadap 3 kegiatan,yaitu,membuat waduk Jragung dibagian atas ,menyudet Bendung Ploso untuk pengembalian aliran Jragung dengan normalisasi sungai dan sungai Cabean.

Bendung Ploso dan Guntur juga mengalami sedimentasi yang tinggi,maka dari itu selain dikeruk,tumpukan sampah di Bendungan Guntur juga membludak menyebabkan penumpukan,yang berasal dari arah hulu ,dari pihak perhutani juga meminta agar difasilitasi oleh Pemprov.Dengan adanya dialog antara
Pemerintah Kabupaten Demak dan Perhutani pesoalan tumpukan sampah,dan masalah-masalah kecil lainnnya dapat diselesaikan dan dapat membangun sumber daya air yang baik.

DAS Jragung termasuk dalam wilayah Sungai Jratunseluna, yaitu terletak di bagian utara Jawa Tengah .Posisi koordinat DAS Jragung antara 110021 ' 57 " - 1100 39' 58" BT dan antara 60 50' 55" - 70 13' 59" LS. Secara administratif Daerah Aliran Jragung melewati Kabupaten Semarang, Kota Semarang, Kabupaten Grobongan, dan Kabupaten Demak ,dengan bagian hulu mencakup Kecamatan Ambarawa dan Kecamatan Bawen (Kabupaten Semarang) sedangkan bagian hilir berada di Kabupaten Demak. Berikut merupakan gambaran wilayah Sungai Jratunseluna beserta Peta Luas Das Sungai Jragung:

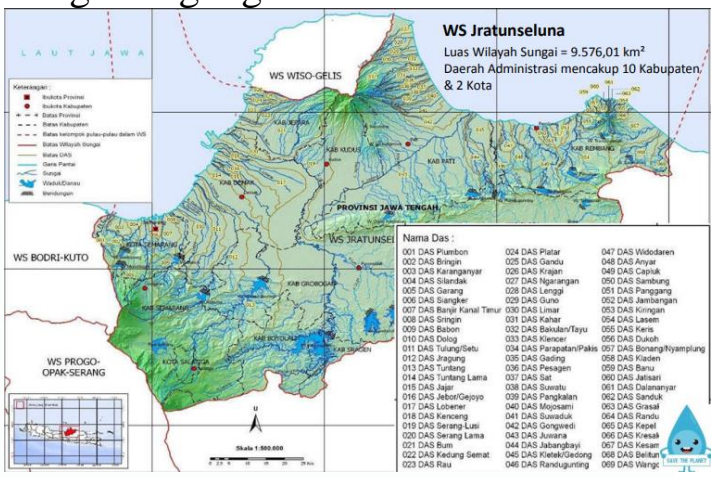

Gambar 1. Peta Wilayah Sungai Jratunseluna

(Sumber : https://bpbd.jatengprov.go.id/wpcontent/uploads/2019/06/Potensi-Air-BersihPenanganan-Kekeringan-25juni201901.pdf)

Tujuan dari Pembuatan Jurnal dengan Judul Pengendalian Bnajir terhadap Sungai Jragung Dukuh Wangun Desa Rejosari Kecamatan Karangawen, Kabupaten Demak adalah: 
1. Untuk mengembalikan fungsi Sungai dan mengatasi banjir yang sering terjadi di Kabupaten Demak khususnya di Kecamatan Guntur,Karangawen dan Mranggen.

2. Pengembalian Arus Sungai

3. Untuk perbaikan jembatan di sungai yang membentang sejauh 75 kilometer meliputi Jragung, Cabean, hingga Wonokerto.

\section{METODE PENELITIAN}

Perencanaan didalam pengendalian banjir Sungai Jragung di Desa Rejosari,Kabupaten Demak dilakukan dengan metode penelitian sebagai berikut:

1. Metode yang pertama dipakai dengan penelitian yang dilakukan di alam adalah menggambarkan daerah penelitian Sungai Jragung. Penggambaran daerah ini dilakukan agar dapat memahami kondisi, luas daerah Sungai Jragung dan dapat mengetahui permasalahan yang ada disekitar dan dapat memberikan saran ataupun solusi yang terbaik didalam penanganan banjir di Daerah Rejosari,Kabupaten Demak.

2. Pengumpulan Data

Pada penelitian pengendalian banjir sungai ada beberapa langkah-langkah yang harus diidentifikasi,yaitu diantaranya:

a. Data Sekunder,data yang didapatkan dari berbagai sumber instansi,ataupun lembaga yang terkait ,berupa data yang sudah lama dengan data kondisi terbaru.Diantaranya adalah peta DEM,Peta DAS,Data Curah Hujan,Peta Lokasi Stasiun Hujan dan data tanah.

b. Data Pendukung,data yang dipergunakan dalam masa pertimbangan secara menyeluruh dengan beberapa tambahan data,seperti tata guna lahan,data kependudukan dan administrasi pemerintahan.

3. Analisis Data

Analisis Data yang digunakan berupa data yang sudah dicari dengan data sekunder serta pendukung dalam melengkapi analisa data pada penelitian ini.

4. Perencanaan Konstruksi

Perencanaan Konstruksi disepanjang sungai dan bangunan utama,dengan mengananlisi kestabilan tanggul dan memperhatikan bahaya kelongsoran,Dimensi yang harus aman akibat limpasan air ,maka semua memperlukan pertimbangan elevasi muka air banjir,kondisi topografi dan keadaan sekitar.

5. Metode Pelaksanaan

Metode yang dilakukan dalam penelitian ini dapat berupa kerja dalam penanganan sungai akibat limpasan air yang kuat dalam penanganannya.

\section{HASIL DAN PEMBAHASAN \\ a. Letak Geografis}

Keberadaan Sungai Jragung di Kecamatan Karangawen, Kecamatan Karangawen yang berada di Kabupaten Demak.Secara geografis, Kecamatan Krangawen terletak diantara $110^{\circ} 30^{\prime}$ 36" hingga $110^{\circ} 37^{\prime} 10^{\prime \prime}$ Bujur Timur dan $7^{0} 0^{\prime} 24^{\prime \prime}$ hingga $7^{0} 8^{\prime} 23^{\prime \prime}$ Lintang Selatan.Secra administrasi, Kecamatan Karanganyar yang berada pada batas langsung Kecamatan Guntur bagian utara,Kabupaten Grobogan bagian timur,Kabupaten Semarang bagian selatan dan Kecamatan Mranggen bagian barat. 
Dibawah ini merupakan gambar Peta Administrasi Kecamatan Karangawen :

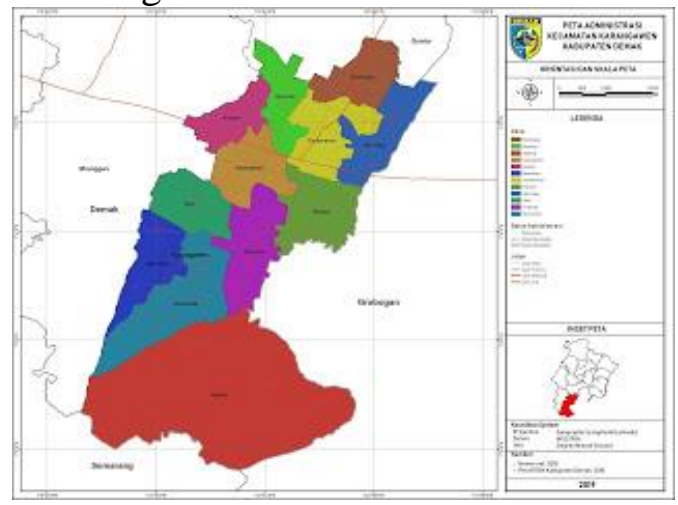

Gambar 2. Peta Administrasi Kecamatan Karangawen

(Sumber:

https://neededthing.blogspot.com/2019/08/pet a-administrasi-kecamatan-karangawen.html)

Kecamatan Karangawen memiliki 12 desa atau kelurahan, diantaranya merupakan desa yang terdapat di Kecamatan Karangawen, Kabupaten Demak:

1. Desa Margohayu

2. Desa Teluk

3. Desa Jragung

4. Desa Karangawen

5. Desa Wonosekar

6. Desa Tlogorejo

7. Desa Brambang

8. Desa Rejosari

9. Desa Pundenarum

10. Desa Sido Rejo

11. Desa Bumirejo

12. Desa Kuripan

\section{b. Luas Wilayah}

Kecamatan Karangawen adalah menjadi salahsatu kecamatan di Kabupaten Demak,Kecamatan Karangawen mempunyai perbatasan wilayah dengan kecamatan lainnya diantaranya adalah: a. Sebelah Utara : Guntur dan sekitarnya

b. Sebelah Timur : Tegowanu dan Grobogan.

c. Sebelah Selatan : Klepu dan Kabupaten Semarang.

d. Sebelah Barat : Kecamatan Mranggen

Berikut ini merupakan Persentase Luas Wilayah Desa Kecamatan Karangawen:

Tabel 1. Luas Wilayah Desa di Kecamatan Karangawen

\begin{tabular}{cccc}
\hline No. & Desa & Luas & $\begin{array}{c}\text { Persentase } \\
\%\end{array}$ \\
\hline 1. & Jragung & 11,84 & 17,69 \\
\hline 2. & Wonosekar & 13,02 & 19,44 \\
\hline 3. & Margohayu & 3,05 & 4,56 \\
\hline 4. & Tlogorejo & 4,71 & 7,04 \\
\hline 5. & Teluk & 3,24 & 4,84 \\
\hline 6. & Rejosari & 5,56 & 8,31 \\
\hline 7. & Karangawen & 4,67 & 6,82 \\
\hline 8. & Kuripan & 2,62 & 3,91 \\
\hline 9. & Bumirejo & 3,61 & 5,39 \\
\hline 10. & Brambang & 5,05 & 7,53 \\
\hline 11. & Sidorejo & 5,23 & 7,81 \\
\hline 12. & Pundenarum & 4,45 & 6,65 \\
\hline & Jumlah & 66,96 & 100,0 \\
\hline Tahun 2013 & 66,96 & 100,0 \\
\cline { 2 - 3 } Tahun 2012 & 66,96 & 100,0 \\
\cline { 2 - 3 } Tahun 2011 & 66,96 & 100,0 \\
\hline
\end{tabular}

(Sumber:https://neededthing.blogspot.com /2019/08/peta-administrasi-kecamatankarangawen.html) 
Berdasarkan perbatasan Kecamatan Karangawen diatas,perbatasan dengan kecamatan lain, Desa Rejosari, Kecamatan Karangawen berjarak dejauh dari ibukota kecamatan yaitu Desa Margohayu sejauh 9,5 km dan perbatasan terdekat yakni $1 \mathrm{~km}$ Desa Karangawen.Dari ibukota menuju Kabupaten Demak sejauh 22,5 $\mathrm{km}$,begitupun dengan jarak yang bisa ditempuh ibukota Kecamatan Guntur yakni $8,5 \mathrm{~km}$.

\section{c. Luas DAS Sungai Jragung}

Daerah Aliran Sungai Jragung melewati kabupaten Semarang,Kota Semarang bahkan Kabupaten Grobogan dan Kabupaten Demak.Bagian hulu yang didalamnya terdapat kecamatan Ambarawa dan Bawen(Kabupaten Semarang),dan bagian hilir di Kabupaten Demak.

Dibawah merupakan tabel dari Luas DAS Jragung berdasarkan batas administratif:

Tabel 2. Luas DAS Jragung berdasrkan batas administratif

\begin{tabular}{|l|c|}
\hline Nama Kabupaten & Luas (Ha) \\
\hline Kab. Semarang & 13057,73 \\
\hline Kota Semarang & 310,41 \\
\hline Kab. Grobogan & 13131,809 \\
\hline Kab. Demak & 26964,54 \\
\hline
\end{tabular}

(sumber:https://neededthing.blogspot.co $\mathrm{m} / 2019 / 08 /$ peta-administrasikecamatan-karangawen.html)

Dengan luas 53464,49 Ha wilayah DAS Jragung menjadi satu-satunya sungai utama,dengan luas yang cukup luas dengan memiliki anak sungai Kali Jragung Lama,Kali Banteng 1, Kali Banteng 15,dan Kali Cabean.DAS Jragung juga terdapat 4 Sub DAS diantaranya yakni,:
b. SubDAS Wonokerto
c. SubDAS Trimo
d. SubDAS Klampok

Dibawah ini merupakan Tabel karakteristik SubDAS sebagai berikut:

Tabel 3. Tabel karakteristik SubDAS

\begin{tabular}{ccc}
\hline $\begin{array}{l}\text { Nama } \\
\text { SubDAS }\end{array}$ & $\begin{array}{l}\text { Total } \\
\text { Panjang } \\
\text { Sungai } \\
\mathbf{( K m )}\end{array}$ & $\begin{array}{l}\text { Kerapatan } \\
\text { Aliran } \\
\mathbf{( k m / k m 2})\end{array}$ \\
\hline Lana & 209,53 & 1,34 \\
\hline Klampok & 82,49 & 1,30 \\
\hline Trimo & 73,80 & 1,48 \\
\hline Wonokerto & 527,38 & 1,57 \\
\hline \multicolumn{3}{c}{ (Sumber :media.neliti.com) }
\end{tabular}

Dibawah ini juga merupakan Gambar WS Seluna dengan 4 sistem sungai dan Peta DAS Jragung:

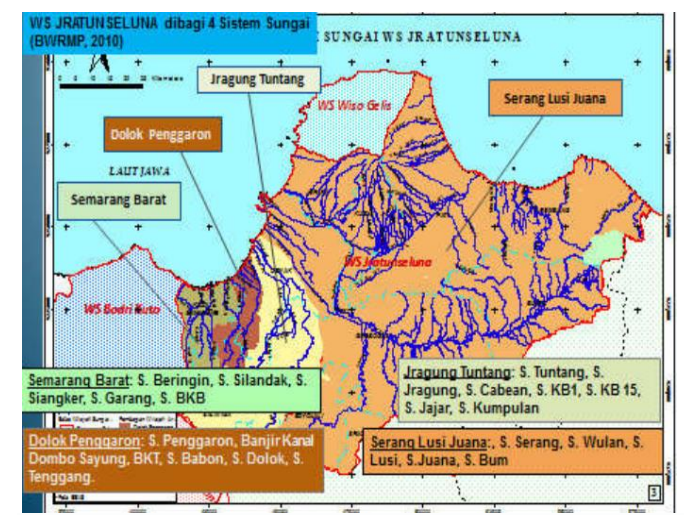

Gambar 3. WS Seluna dengan 4 sistem sungai (BWRMP, 2010)

\section{a. SubDAS Lana}




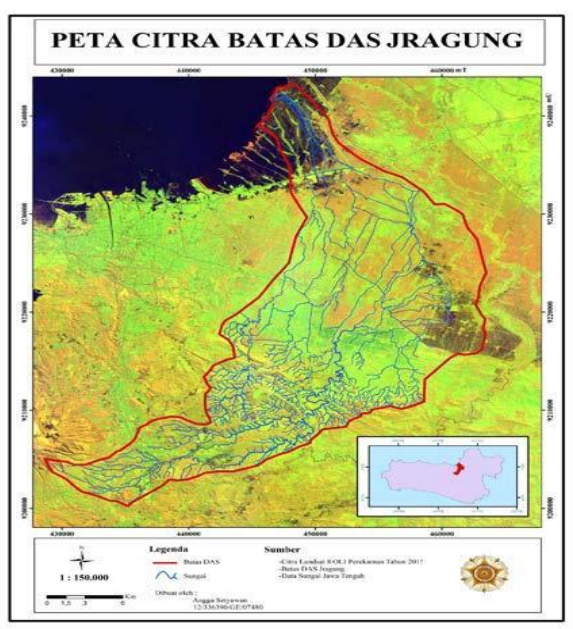

Gambar 4. Peta Luas DAS Jragung

(Sumber: media.neliti.com)

\section{d. Data Curah Hujan}

Data curah hujan yang akan dianalisa pada wilayah studi diperlukan beberapa informasi stasiun pengamatan terdekat disekitar daerah yang akan diteliti.Penempatan atau dengan pelaksaan sesuai kriteria yang sudah ada yaitu:

$>$ Memiliki debit dengan periode pengamatan panjang(minimal 5 tahun)

$>$ Memiliki data tahunan lengkap,tidak banyak data yang berisi data kosong

Lokasi pengamatan curah hujan terletak didalam sekitar studi berdasarkan curah hujan.Didalam studi ini terdapat 4 pos penakar curah hujan diantaranya adalah Sta Banyumenen, Sta. Brumbung, Sta. Bawen, Sta. Jragung dengan periode pengamatan dari tahun 2014 s.d 2018 (5 tahun).

Tabel 4. Jumlah Curah Hujan Bulanan Bd. Jragung Klimatologi

\begin{tabular}{ccccccc}
\hline \multirow{2}{*}{ Tahun } & \multicolumn{7}{c}{ Bulan } \\
\cline { 2 - 7 } & Jan & Feb & Mar & Apr & May & Jun \\
\hline 2014 & 225,0 & 241,0 & 185,0 & 297,0 & 88,0 & 89,0 \\
\hline
\end{tabular}

\begin{tabular}{|c|c|c|c|c|c|c|c|c|}
\hline & 2015 & & & & 21 & & & \begin{tabular}{|ll}
29,0 & 0,0
\end{tabular} \\
\hline & 2016 & & & & & & & 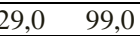 \\
\hline & 2017 & & & & & & & 29,0 \\
\hline & 2018 & & & & 87 & & & 72,0 \\
\hline & & & & Bula & & & & Jumlah \\
\hline Jun & Jul & Aus & $\mathrm{Se}_{1}$ & $\mathrm{O}$ & & Nov & Dec & Tahunan \\
\hline 89 & $\begin{array}{l}18 \\
2,\end{array}$ & 450 & 00 & 31 & & 2860 & 227. & 1896,0 \\
\hline & 0 & & & & & & 146 & 1400,0 \\
\hline 0,0 & 0 & 1,0 & 0,0 & 4, & & 247,0 & 0 & \\
\hline $\begin{array}{c}99, \\
0\end{array}$ & $\begin{array}{c}0, \\
0\end{array}$ & 68,1 & $\begin{array}{c}262 \\
0\end{array}$ & $\begin{array}{r}20 \\
0\end{array}$ & & 247,0 & $\begin{array}{c}236 \\
0\end{array}$ & 1993,0 \\
\hline $\begin{array}{c}29, \\
0\end{array}$ & $\begin{array}{c}9, \\
0\end{array}$ & 13, & 13, & 83 & & 518,0 & $\begin{array}{c}125 \\
0\end{array}$ & 1449,0 \\
\hline 72, & 0, & & & & & & 231 & 18896 \\
\hline 0 & 0 & 228 & 1 & 42 & & 291,0 & & \\
\hline
\end{tabular}
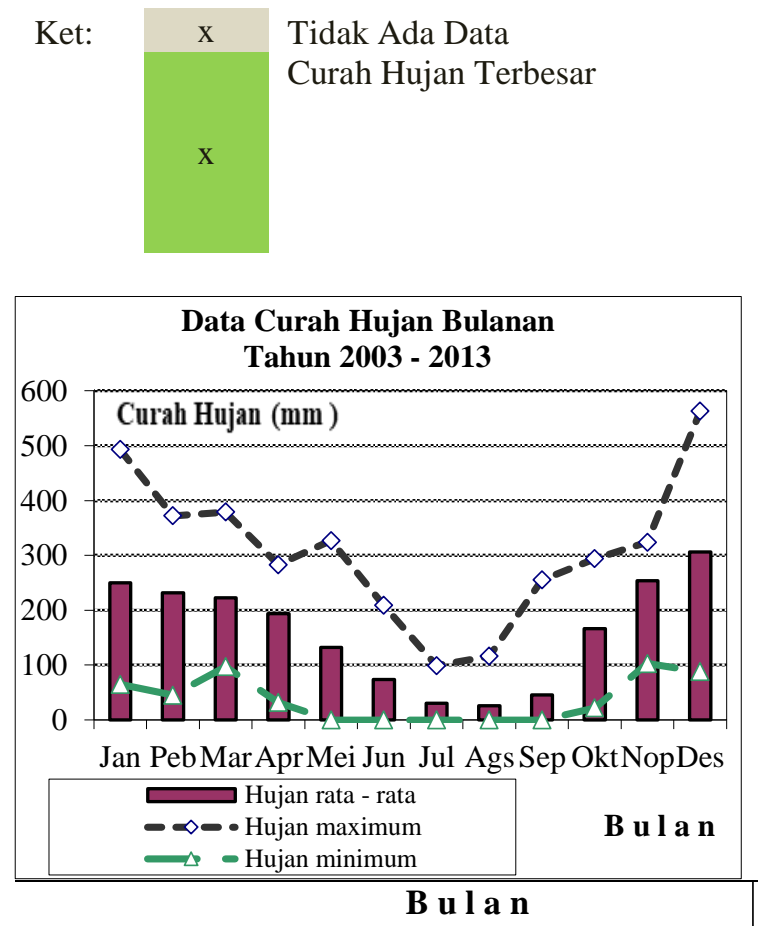

Tahun Jan Peb Mar Apr Mei Jun

\begin{tabular}{ccccccc}
\hline 2003 & 127 & 229 & 117 & 177 & 85 & 4 \\
\hline 2004 & 159 & 232 & 204 & 176 & 270 & 8 \\
\hline 2005 & 270 & 239 & 326 & 216 & 29 & 117 \\
\hline 2006 & 433 & 372 & 226 & 258 & 206 & 7 \\
\hline 2007 & 65 & 165 & 347 & 169 & 0 & 0 \\
\hline 2008 & 270 & 370 & 208 & 238 & 140 & 49 \\
\hline 2009 & 148 & 163 & 97 & 32 & 112 & 63 \\
\hline 2010 & 179 & 45 & 379 & 283 & 327 & 151 \\
\hline
\end{tabular}




\begin{tabular}{lcccccc}
\hline 2011 & 230 & 213 & 166 & 201 & 190 & 54 \\
\hline 2012 & 493 & 334 & 154 & 177 & 11 & 17 \\
\hline 2013 & 315 & 209 & 225 & 200 & 109 & 209 \\
\hline 2014 & 315 & 209 & 225 & 200 & 109 & 209 \\
\hline & & & & & & \\
\hline Max & $\mathbf{4 9 3}$ & $\mathbf{3 7 2}$ & $\mathbf{3 7 9}$ & $\mathbf{2 8 3}$ & $\mathbf{3 2 7}$ & $\mathbf{2 0 9}$ \\
\hline Rerata & $\mathbf{2 5 0 ,}$ & $\mathbf{2 3 1}$ & $\mathbf{2 2 2}$ & $\mathbf{1 9 3 ,}$ & $\mathbf{1 3 2}$ & $\mathbf{7 4 ,}$ \\
Min & $\mathbf{6 5}$ & $\mathbf{4 5}$ & $\mathbf{9 7}$ & $\mathbf{3 2}$ & $\mathbf{0}$ & $\mathbf{0}$ \\
\hline
\end{tabular}

3. Pada tahun 2005 terjadi hujan,terjadi hujan tahunan sebesar 2099 dengan R24 sebesar 136

4. Pada tahun 2006 terjadi hujan,terjadi hujan tahunan sebesar 2157 dengan R24 sebesar 124

5. Pada tahun 2007 terjadi hujan,terjadi hujan tahunan sebesar 1594 dengan R24 sebesar 97

6. Pada tahun 2008 terjadi hujan,terjadi hujan tahunan sebesar 901 dengan R24 sebesar 98

7. Pada tahun 2009 terjadi hujan,terjadi hujan tahunan sebesar 2664 dengan R24 sebesar 188

8. Pada tahun 2010 terjadi hujan,terjadi hujan tahunan sebesar 1733 dengan R24 sebesar 113

9. Pada tahun 2011 terjadi hujan,terjadi hujan tahunan sebesar 1875 dengan R24 sebesar 131

10. Pada tahun 2012 terjadi hujan,terjadi hujan tahunan sebesar 1875 dengan R24 sebesar 131

11. Pada tahun 2013 terjadi hujan,terjadi hujan tahunan sebesar 2169 dengan R24 sebesar 167

12. Pada tahun 2014 terjadi hujan,terjadi hujan tahunan sebesar 2169 dengan R24 sebesar 167.

\section{Stasiun Hidrologi}

Dari hasil data hujan bulanan selama 10 tahun berturut-turut tahun 20032013, dapat disimpulkan sebagai berikut:

1. Pada tahun 2003 terjadi hujan,terjadi hujan tahunan sebesar 1662 dengan R24 sebesar 125

2. Pada tahun 2004 terjadi hujan,terjadi hujan tahunan sebesar 2001 dengan R24 sebesar 125

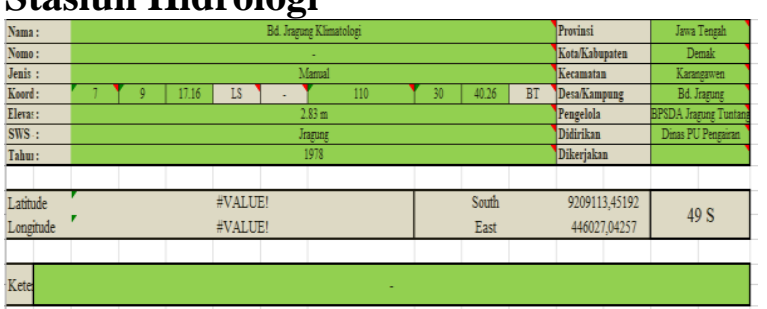

(Sumber:http://pusdataru.jatengprov.go.id/dokume n/hidrologi/2019/5 Bendung Jragung.pdf) 


\section{KESIMPULAN}

Berdasarkan hasil pembahasan dan analisa,maka dapat disimpulkan sebagai berikut:

a. Hujan Maksimal didalam periode tahun 2003-2014 selama 10 tahun di Desa Jragung sebesar 2664 ,curah hujan dapat terjadi dalam kurun 5 periode.

b. Hujan Rerata didalam periode tahun 2003-2014 selama 10 tahun di Desa Jragung sebesar 1929,3.

c. Hujan Minimal didalam periode tahun 2003-2014 selama 10 tahun di Desa Jragung sebesar 901 .

\section{DAFTAR PUSTAKA}

Humas Pemprof Jateng. (18 Maret 2015). "Banjir Demak Akibat Gagalnya Sistem Alur Sungai Jragung". http://pusdataru.jatengprov.go.id/iNE WS/banjir-demak-akibat-gagalnyasistem-alur-sungai-jragung/

Imantara, Alaqsha Gilang. (11 November 2018). " "Proyek Pengendalian banjir Sistem Sungai Jragung Ditargetkan Rampung Akhir Desember 2018". https://jateng.tribunnews.com/2018/1 1/11/proyek-pengendalian-banjirsistem-sungai-jragung-ditargetkanrampung-akhir-desember-2018

Setiawan, Wikha. (20 Juli 2017). "Atasi Banjir, Proyek Sungai Jragung di Demak Dikebut". https://news.detik.com/berita-jawatengah/d-3567477/atasi-banjirproyek-sungai-jragung-di-demakdikebut

Jumlah Curah Hujan Bulanan Bd. Jragung Klimatologi. (Februari 2018) http://pusdataru.jatengprov.go.id/dok
umen/hidrologi/2019/5_Bendung_Jra gung.pdf

Kreasi Geologi. (16 Agustus 2019). "Peta Administrasi Kecamatan Karangawen, Kabupaten Demak". https://neededthing.blogspot.com/201 9/08/peta-administrasi-kecamatankarangawen.html

Potensi Air Bersih di Wilayah Pemali Juana dalam Rangka Penanganan Dampak Kekeringan. https://bpbd.jatengprov.go.id/wpcontent/uploads/2019/06/Potensi-AirBersih-Penanganan-Kekeringan25juni201901.pdf 